\title{
Childhood Adversity and Perceived Distress from the COVID-19 Pandemic
}

\author{
Karina M. Shreffler ${ }^{1}$ (D) Christine N. Joachims ${ }^{1} \cdot$ Stacy Tiemeyer $^{1} \cdot$ W. Kyle Simmons ${ }^{2} \cdot$ T. Kent Teague $^{3}$. \\ Jennifer Hays-Grudo ${ }^{4}$
}

Accepted: 15 January 2021 / Published online: 28 January 2021

(C) Springer Nature Switzerland AG 2021

\begin{abstract}
Childhood exposure to adversity may increase an individual's reactivity to subsequent stressors. In this paper, we examine how adverse childhood experiences (ACEs) are associated with experiencing greater perceived distress during the pandemic. In this volunteer clinical cohort study, 177 pregnant women (ages 16-38) were recruited from two university-affiliated perinatal clinics located in a small metropolitan city between October 2017 and May 2018. Longitudinal data collection is ongoing. The current study includes the 101 women who participated through the eighth and most recent survey conducted in mid-April 2020. OLS regression analyses were used to examine the association between childhood adversity and pandemic-related distress. We found that ACE scores were associated with higher levels of distress $(b=.08$; se $=.03 ; p<.01)$ when controlling for demographic characteristics. The addition of loneliness to the model fully mediates the association between ACEs score and distress. Findings suggest that adverse childhood experiences influence COVID-19-related distress due to greater social isolation. Those who had greater adversity during childhood may be less likely to have the social connectedness needed to reduce distress due to the pandemic.
\end{abstract}

Keywords COVID-19 $\cdot$ ACEs $\cdot$ Adversity $\cdot$ Childhood experiences $\cdot$ Stress $\cdot$ Isolation

By the beginning of December 2020, 64.1 million cases of coronavirus disease (COVID-19) had been confirmed globally, with the USA leading with more than 13.7 million infections and at least 271,000 deaths (Johns Hopkins University and Medicine, 2020). In addition to the health and mortality risks associated with COVID-19, the economic and social consequences of widespread efforts to "flatten the curve" are unprecedented. The national unemployment rate and decline in real GDP since the start of the pandemic are historically high (Bureau of Economic Analysis, 2020; Kochhar, 2020). There are also substantial costs for mental health, particularly

Karina M. Shreffler

karina.shreffler@okstate.edu

1 Department of Human Development and Family Science, Oklahoma State University, 700 N. Greenwood Ave., Tulsa, OK 74106, USA

2 Department of Pharmacology and Physiology, Oklahoma State University Center for Health Sciences, Tulsa, OK, USA

3 Department of Surgery, University of Oklahoma Health Sciences Center, Tulsa, OK, USA

4 Department of Psychiatry and Behavioral Sciences, Oklahoma State University Center for Health Sciences, Tulsa, OK, USA for those who are already socially and economically vulnerable (Williams, Armitage, Tampe, \& Dienes, 2020). A recent review of the psychological impact of sheltering at home among the general population indicated increased anger, loneliness, posttraumatic stress symptoms, and substance use (Serafini et al., 2020). Prior studies on widespread crises (e.g., natural disasters and recessions) suggest that some members of the population are more vulnerable to crises and that economic and psychosocial consequences can persist for years (Cutter \& Finch, 2008; Dagher, Chen, \& Thomas, 2015; Masozeraa, Bailey, \& Kerchner, 2007; Thomas, Phillips, Lovekamp, \& Fothergill, 2013). Identifying factors that increase perceived distress from the current pandemic therefore has critical practice and policy implications.

Childhood exposure to trauma or stress may increase an individual's reactivity to subsequent stressors such as a pandemic or natural disaster (Hammen, Henry, \& Daley, 2000; Smid et al., 2012). Childhood adversity, as measured by the adverse childhood experiences (ACEs) scale (Felitti et al., 1998), has been identified as a powerful predictor of mental and physical health. To the best of our knowledge, no study has examined the association between childhood adversity and pandemic-related distress. Utilizing a longitudinal cohort 
of women recruited before the pandemic and longitudinally assessed at eight time points between 2017 and 2020, we hypothesized that higher ACE scores would predict increased perceived distress in response to the COVID-19 pandemic, and that economic and social consequences or health fears due to the pandemic would mediate this association.

\section{Data and Methods}

The study was reviewed and approved by the authors' Institutional Review Board before data collection began. In this clinical cohort study, 177 racially diverse and lowincome pregnant women (ages 16-38) were recruited from two university-affiliated perinatal clinics located in a small metropolitan city between October 2017 and May 2018. Longitudinal survey data collection is ongoing, and the current study includes the 101 women who participated through the eighth and most recent survey conducted in April/May, 2020. Participants' childhood experiences and demographic characteristics were assessed during pregnancy. The most recent survey inquired about health, social, and economic impacts as well as perceived change in stress and well-being attributed to the pandemic (i.e., perceived distress). Ordinary least squares regression analyses were used to examine associations between childhood adversity and perceived distress from the COVID-19 pandemic. The first model includes the demographic control variables only; the second model adds ACE score, and the third model adds work hours reduction, loneliness, and health fears.

\section{Results}

Descriptive statistics for the study variables are presented in Table 1. On average, the mean of COVID-19 distress was near the mid-point of the scale. The average ACE score was 3 $(\mathrm{SD}=2.88)$. The sample is diverse in terms of race/ethnicity, with $40 \%$ of participants reporting White, $28 \%$ reporting Black, $14 \%$ reporting Hispanic, and $18 \%$ reporting Native American racial/ethnic status, respectively. Approximately $58 \%$ of participants were living in a union, and the average age was $25(M=25.16$; $\mathrm{SD}=5.54)$. The average years of education were above 12 , indicating a high school diploma. Approximately half of the participants reported that they or someone living in their home was laid off from work or experienced a reduction in work hours during the pandemic $(M=.50 ; \mathrm{SD}=.50)$. The average loneliness scale score was $16(\mathrm{SD}=5.61)$. The mean score of health concerns (self or family member) was at about the mid-point of the range $(M=5.48 ; \mathrm{SD}=2.67)$.

The results for the regression analysis are presented in Table 2. After controlling for demographic characteristics
Table 1 Descriptive statistics of study variables $(N=101)$

\begin{tabular}{llll}
\hline Variables & $M$ & $S D$ & Range \\
\hline COVID-19 distress & 3.39 & .86 & $1-5$ \\
Sociodemographic variables & & & \\
$\quad$ White & .40 & .49 & $0-1$ \\
Black & .28 & .45 & $0-1$ \\
Hispanic & .14 & .34 & $0-1$ \\
Native American & .18 & .38 & $0-1$ \\
Married or cohabiting & .58 & .50 & $0-1$ \\
Age & 25.16 & 5.54 & $16-38$ \\
Education (years) & 12.79 & 1.95 & $8-19$ \\
ACE Score & 3.00 & 2.88 & $0-10$ \\
COVID-19 context & & & \\
Work reduction & .50 & .50 & $0-1$ \\
Loneliness & 16.00 & 5.61 & $8-29$ \\
Health concerns & 5.48 & 2.67 & $2-10$ \\
\hline
\end{tabular}

such as age, ethnicity, and education, individuals who reported more childhood adversity also reported increased stress and poorer mental health due to the pandemic $(b=.08 ; p<.01)$. This effect, however, was fully mediated by self-reported loneliness, suggesting that adverse childhood experiences influence distress due to the pandemic due to social isolation. Interestingly, although approximately half of participants reported some economic impacts and health fears due to the pandemic, these were not significantly associated with perceived distress.

\section{Discussion}

The primary goal of this study was to examine whether childhood adversity was associated with greater distress related to the COVID-19 pandemic. Results indicate that even after controlling for demographic characteristics such as age, ethnicity, and education, individuals who reported more childhood adversity also reported increased stress and poorer mental health due to the pandemic. This finding is aligned with prior research indicating childhood adversity sensitizes individuals to subsequent life event stressors and increases risk for psychopathology (Hammen et al., 2000; McLaughlin, Conron, Koenen, \& Gilman, 2010; Stroud, 2018). The association between childhood adversity and increased distress due to the pandemic, however, was fully mediated by self-reported loneliness, suggesting that adverse childhood experiences influence COVID-19 pandemic stress and mental health through individuals' perceived social isolation.

Interestingly, although at least half of participants reported some economic impacts (e.g., job loss or reduction in work hours for themselves or a household member) and health fears 
Table 2 Linear regression analysis of COVID-19 distress by sociodemographic characteristics, ACE score, and COVID-19 context $(N=101)$

\begin{tabular}{|c|c|c|c|c|c|c|c|c|c|}
\hline \multirow[b]{2}{*}{ Variables } & \multicolumn{3}{|c|}{ Model 1} & \multicolumn{3}{|c|}{ Model 2} & \multicolumn{3}{|c|}{ Model 3} \\
\hline & $b$ & & $S E$ & $b$ & & $S E$ & $b$ & & $S E$ \\
\hline \multicolumn{10}{|c|}{ Sociodemographic variables } \\
\hline \multicolumn{10}{|l|}{ White (ref) } \\
\hline Black & -.03 & & .26 & .07 & & .25 & -.01 & & .25 \\
\hline Hispanic & .52 & & .29 & .61 & $*$ & .28 & .61 & $*$ & .28 \\
\hline Native American & .33 & & .27 & .35 & & .26 & .15 & & .27 \\
\hline Married or cohabiting & .35 & & .21 & .36 & & .20 & .39 & & .20 \\
\hline Age & .06 & $* *$ & .02 & .05 & $* *$ & .02 & .06 & $* *$ & .02 \\
\hline Education (years) & -.05 & & .05 & -.03 & & .05 & -.04 & & .05 \\
\hline ACE Score & & & & .08 & $* *$ & .03 & .04 & & .03 \\
\hline \multicolumn{10}{|l|}{ COVID-19 context } \\
\hline Work reduction & & & & & & & .07 & & .18 \\
\hline Loneliness & & & & & & & .05 & $*$ & .02 \\
\hline Health concerns & & & & & & & -.04 & & .04 \\
\hline Constant & 2.19 & $*$ & .82 & 1.74 & $*$ & .81 & 1.29 & & .82 \\
\hline
\end{tabular}

$* * * p<.001$

$* * p<.01$

$* p<.05$

(e.g., concerns that they or a member of their household would contract the virus) due to the COVID-19 pandemic, these were not significantly associated with perceived distress. It is possible that because participants were surveyed approximately 1 month after the start of social distancing efforts, the longer term implications of the pandemic were not fully realized. Future research is needed to investigate longer term psychological impacts of the pandemic. Additionally, because our data drew from a low-income sample of pregnant women who experienced nearly twice as many adverse childhood experiences $(M=3.0)$ than the general population $(M=1.57$; Merrick, Ford, Ports, \& Guinn, 2018), our findings may not be generalizable to other groups with different levels and types of childhood adversities. Future research that examines stress sensitization among a national sample could reveal more representative trends. Despite this limitation, our finding suggests that assessing early life trauma or adversity may help to identify those in need of additional supports or intervention due to the COVID-19 pandemic. Finally, additional research is needed to examine whether the mediating role of loneliness on the association between ACEs and distress is due to smaller social/familial networks. Social connectedness may be a critical buffer for some of the psychological impacts of COVID19 , and those who had greater adversity during childhood may be less likely to have the social connectedness needed to help weather this storm.

Acknowledgements The authors would like to thank the HATCH Project participating perinatal clinics at OU-Tulsa and OSU-CHS and particularly Drs. Karen Gold, Jameca Price, and Lance Frye for their support.
Funding This research was supported by the National Institute of General Jennifer Hays-Grudo, PI). The sponsor was not involved in the study design, collection, analysis, interpretation of findings, the writing of this report, or the decision to submit the article for publication.

Data Availability The datasets used and/or analyzed during the current study are available from the corresponding author upon request.

\section{Declarations}

Ethics Approval and Consent to Participate The [Author blinded] Institutional Review Board (IRB) approved this study.

Consent for Publication Not applicable.

Competing Interests The authors declare no competing interests.

Disclaimer The content is solely the responsibility of the authors and does not necessarily represent the official views of the National Institutes of Health.

\section{References}

Bureau of Economic Analysis. (2020). Gross Domestic Product, Second Quarter 2020 (Advance Estimate) and Annual Update. https://www. bea.gov/sites/default/files/2020-07/tech2q20_adv.pdf. Accessed Jul 31, 2020.

Cutter, S. L., \& Finch, C. (2008). Temporal and spatial changes in social vulnerability to natural hazards. Proceedings of the National Academy of Sciences, 105, 2301-2306. https://doi.org/10.1073/ pnas.0710375105. Medical Sciences of the National Institutes of Health (P20GM109097; 
Dagher, R. K., Chen, J., \& Thomas, S. B. (2015). Gender differences in mental health outcomes before, during, and after the great recession. PLoS One, 10(5), e0124103. https://doi.org/10.1371/journal.pone. 0124103.

Felitti, V. J., Anda, R. F., Nordenberg, D., Williamson, D. F., Spitz, A. M., Edwards, V., \& Marks, J. S. (1998). Relationship of childhood abuse and household dysfunction to many of the leading causes of death in adults: The adverse childhood experiences (ACE) study. American Journal of Preventive Medicine, 14(4), 245-258. https:// doi.org/10.1016/S0749-3797(98)00017-8.

Hammen, C., Henry, R., \& Daley, S. E. (2000). Depression and sensitization to stressors among young women as a function of childhood adversity. Journal of Consulting and Clinical Psychology, 68, 782787. https://doi.org/10.1037/0022-006X.68.5.782.

Johns Hopkins University and Medicine. (2020). Coronavirus resource center. https://coronavirus.jhu.edu/map.html. Accessed September $1,2020$.

Kochhar, R. (2020). Unemployment rose higher in three months of COVID-19 than it did in two years of the Great Recession. https:// pewrsr.ch/2UADTTZ. Accessed June 30, 2020.

Masozeraa, M., Bailey, M., \& Kerchner, C. (2007). Distribution of impacts of natural disasters across income groups: A case study of New Orleans. Ecological Economics, 63, 299-306. https://doi.org/10. 1016/j.ecolecon.2006.06.013.

McLaughlin, K. A., Conron, K. J., Koenen, K. C., \& Gilman, S. E. (2010). Childhood adversity, adult stressful life events, and risk of past-year psychiatric disorder: A test of the stress sensitization hypothesis in a population-based sample of adults. Psychological Medicine, 40, 1647-1658. https://doi.org/10.1017/ S0033291709992121.

Merrick, M. T., Ford, D. C., Ports, K. A., \& Guinn, A. S. (2018). Prevalence of adverse childhood experiences from the 2011-2014 behavioral risk factor surveillance system in 23 states. JAMA Pediatrics, 172(11), 1038-1044. https://doi.org/10.1001/ jamapediatrics.2018.2537.

Serafini, G., Parmigiani, B., Amerio, A., Aguglia, A., Sher, L., \& Amore, M. (2020). The psychological impact of COVID-19 on the mental health in the general population. QJM: An International Journal of Medicine., 113, 531-537. https://doi.org/10.1093/qjmed/hcaa201.

Smid, G. E., Van der Velden, P. G., Lensvelt-Mulders, G. J., Knipscheer, J. W., Gersons, B. P., \& Kleber, R. J. (2012). Stress sensitization following a disaster: A prospective study. Psychological Medicine, 42(8), 1675-1686. https://doi.org/10.1017/S0033291711002765.

Stroud, C. B. (2018). The stress sensitization model. In K. Harkness \& E. P. Hayden (Eds.), The Oxford Handbook of Stress and Mental Health. Oxford Handbooks Online. New York: Oxford University Press. https://doi.org/10.1093/oxfordhb/9780190681777.013.16.

Thomas, D. S., Phillips, B. D., Lovekamp, W. E., \& Fothergill, A. (2013). Social vulnerability to disasters. CRC Press.

Williams, S. N., Armitage, C. J., Tampe, T., \& Dienes, K. (2020). Public perceptions and experiences of social distancing and social isolation during the COVID-19 pandemic: A UK-based focus group study. BMJ Open. https://doi.org/10.1101/2020.04.10.20061267. 